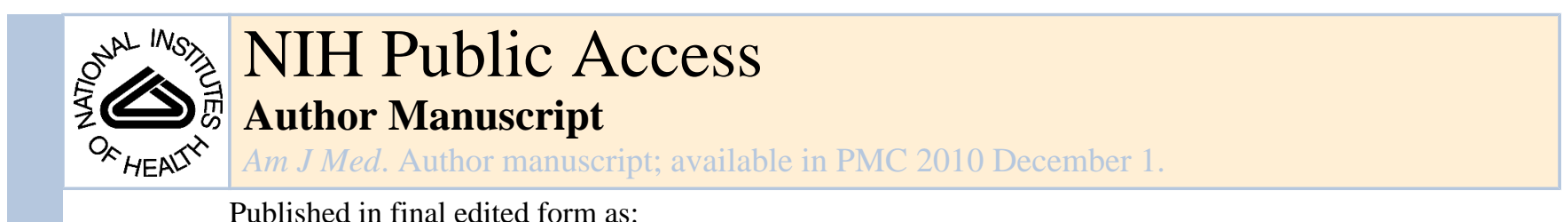

Published in final edited form as:

Am J Med. 2009 December ; 122(12 Suppl): S22. doi:10.1016/j.amjmed.2009.09.008.

\title{
Pathophysiology of Fibromyalgia
}

\author{
Laurence A. Bradley, Ph.D. \\ Division of Clinical Immunology and Rheumatology, University of Alabama at Birmingham, \\ Birmingham, Alabama USA
}

\begin{abstract}
This article reviews the biologic, genetic, and environmental factors that may contribute to the pathophysiology of fibromyalgia. As an affective spectrum disorder, fibromyalgia may share these causal factors with a number of related and co-occurring pain conditions such as irritable bowel syndrome or temporomandibular disorder. There is strong evidence that cardinal pain symptoms of fibromyalgia may be due to alterations in central processing of sensory input, along with aberrations in the endogenous inhibition of pain, Genetic research has shown familial aggregation of fibromyalgia and other related disorders such as major depressive disorder. Exposure to physical or psychosocial stressors, as well as abnormal biologic responses in the autonomic nervous system and neuroendocrine responses, may also contribute to dysfunctional pain processing. As fibromyalgia research continues to progress, it is expected that the pathophysiology of this disorder will be further elucidated, leading to more rational and targeted strategies for the treatment of fibromyalgia patients.
\end{abstract}

\section{Keywords}

Fibromyalgia; affective spectrum disorders; pathophysiology; neuroendocrine system; autonomic nervous system; genetics; environmental stressors

\section{INTRODUCTION}

Fibromyalgia is part of a family of related disorders known as affective spectrum disorders (ASD) that commonly co-occur in individuals and co-aggregate among families.1,2 These disorders share physiologic abnormalities and genetic risk factors that may be central to their etiology. In addition to fibromyalgia, the ASDs encompass a number of psychiatric disorders (e.g., attention-deficit/hyperactivity disorder, bulimia nervosa, dysthymic disorder, generalized anxiety disorder, major depressive disorder [MDD], obsessive-compulsive disorder, panic disorder, posttraumatic stress disorder, premenstrual dysphoric disorder, social phobia) and medical disorders (e.g., irritable bowel syndrome [IBS], migraine, cataplexy).2,3

Request for reprints should be addressed to Laurence A. Bradley, PhD, Division of Clinical Immunology and Rheumatology, 177A Shelby Research Bldg, 1825 University Blvd., Birmingham, Alabama 35294, Braddog@uab.edu.

Laurence A. Bradley, PhD, is a consultant and member of speaker/advisory boards for Forest Laboratories, Inc. and Eli Lilly and Company.

\section{AUTHOR DISCLOSURES}

Dr. Bradley is a consultant for Forest Laboratories, Inc. and Eli Lilly and Company. He has received grant/research support from the National Institutes of Health, the Agency for Healthcare Research and Quality, and the American Fibromyalgia Syndrome Association. $\mathrm{He}$ also is a member of the speakers/advisory board for Forest Laboratories, Inc. and Eli Lilly and Company.

Publisher's Disclaimer: This is a PDF file of an unedited manuscript that has been accepted for publication. As a service to our customers we are providing this early version of the manuscript. The manuscript will undergo copyediting, typesetting, and review of the resulting proof before it is published in its final citable form. Please note that during the production process errors may be discovered which could affect the content, and all legal disclaimers that apply to the journal pertain. 
The pathophysiology of fibromyalgia involves a number of factors, including abnormalities in the neuroendocrine and autonomic nervous systems, genetic factors, psychosocial variables, and environmental stressors. These factors are involved in other disorders that frequently cooccur with fibromyalgia and are also characterized by persistent or recurrent pain and emotional distress, such as IBS and temporomandibular disorder (TMD), and major affective or anxiety disorders.2,4,5 Fibromyalgia may also occur concurrently with chronic inflammatory diseases such as rheumatoid arthritis (RA), osteoarthritis, and systemic lupus erythematosus.6 The presence of 1 or more of these co-occurring conditions may complicate diagnosis and treatment of fibromyalgia. 4 With improved understanding of the pathophysiology of fibromyalgia and related disorders, however, it is expected that more efficacious treatments will become available and healthcare professionals will be able to provide patients with better information concerning prognosis and treatment strategies.

\section{ABNORMAL PAIN SENSITIVITY AND PAIN INHIBITION IN FIBROMYALGIA}

Patients with fibromyalgia display enhanced sensitivity to a wide array of stimuli, such as heat and cold, as well as to mechanical and ischemic pressure. These stimuli produce pain responses in patients when applied at levels of intensity that do not evoke pain responses in healthy individuals. ${ }^{7}$ There is increasing evidence that fibromyalgia is characterized by an augmentation of sensory input that is mediated by central nervous system (CNS) events similar to those associated with neuropathic pain conditions (i.e., central sensitization). ${ }^{8}$ The evidence also suggests that fibromyalgia involves abnormal levels of serotonin and norepinephrine, which are key neurotransmitters in endogenous pain inhibitory pathways.

\section{Mechanisms of Pain Perception}

In the classical model of acute pain, a stimulus is applied to skin or muscle and the sensory input from nerve receptors in these tissues is transmitted along primary afferents (A- $\delta$ and $\mathrm{C}$ nerve fibers) to the dorsal horns of the spinal cord (Figure 1A).${ }^{9}$ The sensory input is then transmitted via second-order spinal neurons that project to the brain, although this input may be altered by physiologic processes that occur in the dorsal horns. For example, activation of descending inhibitory pain pathways involving norepinephrine, serotonin, and endorphins can modulate pain transmission in the spinal cord. ${ }^{10}$

Normally, the primary afferents transmit action potentials to presynaptic terminals in the spinal dorsal horns, where substance $\mathrm{P}$ and excitatory amino acids such as glutamate are released (Figure 1B). These neuropeptides bind to and activate postsynaptic receptors located on second-order pain transmission neurons (PTNs) that ascend and transmit sensory inputs to various regions in the brain, including the thalamus, somatosensory cortices, and the limbic system, which in turn results in the perception of pain. In abnormal pain processing, the PTNs become sensitized to incoming pain signals in response to intense or prolonged exposure to painful stimuli (Figure 1C). One of the mechanisms underlying this sensitization is the overactivation of postsynaptic nitric oxide production, which in turn increases the presynaptic release of excitatory amino acids and causes the PTNs to become hyperexcitable. ${ }^{9}$

Until the 1990's, the activation of glia (i.e., astrocytes and microglia) was not considered relevant to the function of dorsal horn neurons and pain signaling. However, the role of spinal glia in central sensitization and enhanced pain sensitivity has been demonstrated in preclinical studies.11'12 It is now hypothesized that dorsal horn glia are activated by the release of nitric oxide, prostaglandins, fractalkine, substance $\mathrm{P}$, adenosine triphosphate (ATP), and excitatory amino acids from PTNs and primary afferents. The glia, in turn, release proinflammatory cytokines, nitric oxide, prostaglandins, reactive oxygen species, ATP, and excitatory amino acids. In addition to further increasing the release of substance $\mathrm{P}$ and glutamate from the A- $\delta$ and $\mathrm{C}$ afferents, these substances enhance or prolong the hyperexcitability of the PTNs. This 
enhanced excitability drives pain states by augmenting the transmission of pain signals, which results in the allodynic and hyperalgesic responses exhibited by persons with neuropathic pain syndromes.

\section{Evidence for Abnormal Pain Processing in Fibromyalgia Patients}

In both animal and human models of neuropathic pain, the source of sensory input (e.g., nerve injury) is identifiable, and pain sensitivity is reduced when the source is eliminated. In contrast, the source of sensory input among patients with fibromyalgia remains unknown. For this reason, most investigators involved in fibromyalgia research refer to central augmentation of sensory input rather than central sensitization when they discuss the pathophysiology of fibromyalgia. ${ }^{12}$

As discussed in greater detail by Clauw in this supplement, studies in fibromyalgia patients provide evidence that central augmentation of sensory input is associated with enhanced sensitivity to pain. Gracely and colleagues found, ${ }^{13}$ for example, that approximately $50 \%$ lower stimulus intensity is needed to evoke a pain response in patients with fibromyalgia compared to healthy controls $(P<0.001) .{ }^{13}$ When the healthy controls were exposed to the same intensity levels as that administered to patients, they did not experience pain. These findings provide strong evidence that the enhanced pain sensitivity exhibited by fibromyalgia patients is associated with the CNS augmentation of relatively low levels of sensory input that do not produce pain in healthy persons.

Studies conducted by Russell et al14,15 indicate that the painful symptoms of fibromyalgia might also involve aberrations in the descending pain inhibition pathways. As described earlier, the transmission of sensory input to the brain is inhibited by the activation of fibers that descend from brain stem sites to the dorsal horn, primarily through the release of neurotransmitters associated with variations in pain and mood (e.g., norepinephrine and serotonin) (Figure 1A). Among persons with fibromyalgia, the function of this endogenous pain inhibition system may be impaired by deficiencies in CNS levels of these neurotransmitters. Russell and colleagues found that relative to healthy controls, fibromyalgia patients are characterized by low blood serum levels of serotonin ${ }^{14}$ and low cerebrospinal fluid levels of metabolites of serotonin, norepinephrine, and dopamine. ${ }^{15}$ The clinical relevance of these findings are further discussed by Mease in this supplement.

\section{BIOLOGIC ABNORMALITIES IN FIBROMYALGIA}

\section{Neuroendocrine System}

Fibromyalgia is generally considered to be a stress-related disorder that involves abnormal functioning in the hypothalamic-pituitary-adrenal (HPA) axis. Similarly to other psychiatric disorders, fibromyalgia has been associated with the inability to suppress cortisol. In a study conducted by McCain and Tilbe, ${ }^{16}$ for example, it was found that compared to patients with RA, patients with fibromyalgia displayed significantly higher overall plasma cortisol ( $P$ $<0.001$ ) and exhibited higher peak and trough levels of plasma cortisol. Furthermore, 35\% of patients with fibromyalgia treated with dexamethasone were unable to suppress plasma cortisol levels compared to only $5 \%$ of those with RA $(P<0.001)$.

Crofford and colleagues ${ }^{17}$ also found disturbances in HPA axis functioning, including a blunted stress response to ovine corticotropin-releasing hormone and elevated basal trough cortisol levels in fibromyalgia patients. Harris and colleagues ${ }^{18}$ examined relationships between salivary cortisol levels and ratings of pain, fatigue, and stress and reported no differences between patients and controls in terms of cortisol levels or diurnal variations. However, significant associations between cortisol levels and pain ratings were present at time of waking and at 1 hour after waking; no associations between cortisol level and fatigue or stress were 
observed. Together, these studies suggest that patients with fibromyalgia are characterized by disturbances in HPA axis function. However, the relationship between patients' cortisol levels and pain ratings are highly associated only at waking and shortly thereafter.

\section{Autonomic Nervous System}

Aberrations in autonomic nervous system (ANS) functioning are often observed among patients with fibromyalgia. ANS abnormalities may contribute to enhanced pain and other clinical problems associated with fibromyalgia via the alteration of physiologic responses required for effective stress management (e.g., increases in blood pressure) and pain inhibition via diminished production of growth hormone (GH) and insulin-like growth factor (IGF-1).

Alterations in ANS function include decreased microcirculatory vasoconstriction and orthostatic hypotension. Vaerøy and colleagues ${ }^{19}$ found that compared to controls, patients with fibromyalgia had blunted vasoconstriction responses to cold pressor tasks as well as decreased microcirculatory responses to auditory stimulation (all $P<0.05$ ). Bou-Holaigah et $\mathrm{al}^{20}$ reported that during tilt-table testing, $60 \%$ of patients with fibromyalgia exhibited an abnormal drop in blood pressure compared with $0 \%$ of controls $(P<0.001)$. In addition, all of the patients who tolerated the tilt-table test for more than 10 minutes reported a worsening of pain symptoms, whereas control subjects remained asymptomatic. Difficulty in maintaining blood pressure levels may directly contribute to some of the unpleasant symptoms frequently associated with fibromyalgia, such as fatigue and dizziness, as well as affect physiologic responses to stressors.

Martínez-Lavín et al ${ }^{21}$ showed that compared to controls, patients with fibromyalgia may also have significantly lower heart rate variability at the $0.050 \mathrm{~Hz}$ to $0.150 \mathrm{~Hz}$ frequency domain while in a standing position $(-0.057$ vs 0.081 , respectively, $P<0.05)$. The authors suggest that this diminished heart rate variability is due to an abnormal chronobiology that may also contribute to sleep disturbance and fatigue. Stein and colleagues ${ }^{22}$ reported similar findings and observed that heart rate variability may also be sex-dependent, indicating that autonomic mechanisms associated with fibromyalgia may be different in men and women.

\section{Sleep Disturbances}

Patients with fibromyalgia often have problems with sleep, including nonrestorative sleep, insomnia, early morning awakening, and poor quality of sleep. ${ }^{21,23}$ In a study by Roizenblatt and colleagues, ${ }^{23}$ sleep quality was significantly lower in patients with fibromyalgia than in controls $(P=0.04)$, and patients reported worsening of pain symptoms after poor sleep. In polysomnography studies, alpha-delta sleep patterns associated with interrupted and nonrestorative sleep were frequently observed in patients with fibromyalgia. ${ }^{24}$ Sleep disturbances may be related to the reduced energy and fatigue often found among patients with fibromyalgia. Disturbed sleep may also contribute to enhanced pain. Frequent alpha-wave intrusions during delta-wave sleep have been associated with the reduced production of $\mathrm{GH}$ and IGF-1. ${ }^{25,26}$ Given that GH and IGF-1 are necessary for the repair of muscle microtrauma, sleep disturbances may impair the healing of muscle tissue damage, thereby prolonging the transmission of sensory stimuli from damaged muscle tissue to the CNS and enhancing the perception of muscle pain. ${ }^{27}$ In turn, this enhanced pain may contribute to increases in sleep disturbance, thereby maintaining the patient's fatigue and continuing the inadequate muscle tissue repair. Recent evidence from a large epidemiologic study supports the correlation between sleep and pain. ${ }^{28}$ In this study, subjects' self-reports of improvements in restorative sleep were associated with the resolution of chronic widespread pain independently of change in psychological factors. These findings suggest that pharmacologic and nonpharmacologic therapies that improve sleep quality may also help to reduce pain. 


\section{GENETIC AND FAMILY INFLUENCE ON FIBROMYALGIA}

\section{Genetic Evidence for ASDs}

Recent studies2,3,29 in patients with fibromyalgia, RA, or MDD, as well as the first-degree relatives of these individuals, support the ASD hypothesis that certain related disorders may share genetic risk factors. For example, Arnold and colleagues, 3 reported that compared to the first-degree relatives of RA patients, the relatives of fibromyalgia patients more frequently meet the diagnostic criteria for fibromyalgia or MDD and exhibit a greater number of sensitive anatomic sites (i.e., tender points) as defined by the American College of Rheumatology (ACR) classification criteria. ${ }^{30}$ The frequency of fibromyalgia among the first-degree relatives of probands with fibromyalgia and RA were $6.4 \%$ and $1.1 \%$, respectively; the lifetime frequency of MDD diagnoses for these 2 groups of relatives were $29.5 \%$ and $18.3 \%$, respectively; and the frequency of major mood disorders (bipolar disorder or MDD) was $32.1 \%$ and $19.1 \%$, respectively. The median number of tender points among the first-degree relatives of the fibromyalgia probands was 17 out of maximum of 18 , whereas the median number of tender points was 12 out of 18 among the relatives of RA probands. After controlling for the effects of familial aggregation of fibromyalgia, the co-aggregation of fibromyalgia and MDD remained statistically significant.

Hudson and colleagues ${ }^{2}$ further examined the data from the Arnold study in order to determine whether fibromyalgia co-aggregates with ASDs other than the mood disorders. Even after controlling for the presence of mood disorders, they found that $38.6 \%$ of the first-degree relatives of probands with an ASD (78 with fibromyalgia, 12 with other forms of ASD) met the criteria for at least $1 \mathrm{ASD}$, as compared with $31.2 \%$ of the relatives of probands without an ASD. Fibromyalgia significantly co-aggregated with other forms of ASD $(P=0.004)$; among relatives of the 78 probands with fibromyalgia, the lifetime frequency of nonfibromyalgia ASDs was $42.2 \%$, compared with $26.5 \%$ among relatives of the 40 probands with RA. Even after excluding mood disorders, fibromyalgia significantly co-aggregated with 1 or more other forms of ASD $(P=0.012)$. The frequency of nonfibromyalgia ASD excluding mood disorders was $24.2 \%$ among the relatives of the probands with fibromyalgia and $13.6 \%$ among the relatives of probands with RA.

Raphael and colleagues 29 performed a large, population-based investigation that also indicated family aggregation of MDD among the first-degree relatives of fibromyalgia probands. ${ }^{29}$ This study included 4 groups of women who: (1) met diagnostic criteria for fibromyalgia and MDD; (2) had fibromyalgia but not MDD; (3) did not meet criteria for fibromyalgia but were diagnosed with MDD; and (4) did not have either fibromyalgia or MDD. It was hypothesized that if fibromyalgia were an ASD, similarly high rates of MDD would be found among the first-degree relatives of fibromyalgia probands (with or without MDD) and of control subjects with histories of MDD. It was found that the frequencies of depressive disorder among these 3 groups of family members ranged from $37 \%$ to $46 \%$, compared to a frequency of $29 \%$ in the relatives of control subjects who did not meet the criteria for either fibromyalgia or MDD. Moreover, this pattern was particularly strong among female relatives, indicating a sex-linked effect.

The findings from these family studies support the hypothesis that fibromyalgia co-aggregates with other forms of ASD and that there is a genetic component to this relationship. They also suggest, along with results from a Swedish Twin Registry study, ${ }^{31}$ that genetic factors contribute to the enhanced sensitivity to pain in patients with fibromyalgia. In this study of 15,950 eligible twin pairs with reported chronic widespread pain, it was estimated that genetic factors account for $54 \%$ and $48 \%$ of the variance in occurrence of chronic widespread pain among women and men, respectively. No evidence of sex-related differences was found for 
the genetic influence on pain, suggesting that the same sets of genes are responsible for chronic widespread pain in women and men.

\section{Candidate Genes}

Results from several investigations indicate that a single nucleotide polymorphism (SNP) in the serotonin transporter (5-HTT) gene may contribute to enhanced pain sensitivity among patients with fibromyalgia and other ASDs. Offenbaecher and colleagues ${ }^{32}$ were the first to report that the short (S) allele of this SNP (i.e., S/S genotype) in the regulatory region of the 5 -HTT gene occurs significantly more frequently in patients with fibromyalgia than in healthy controls $(31 \%$ vs. $16 \%, P=0.046)$. Cohen and colleagues ${ }^{33}$ subsequently replicated this observation in an independent sample. Consistent with these findings, preliminary data from our laboratory show that both fibromyalgia probands and their siblings exhibit significantly lower blood serum levels of serotonin than healthy controls and their siblings, respectively. ${ }^{34}$

This 5-HTT gene polymorphism has been found to occur more frequently among patients with MDD than in healthy controls, suggesting it to be a shared risk factor for the development of fibromyalgia and MDD. ${ }^{35,36}$ There also is evidence that the presence of this polymorphism may moderate the association between exposure to stressful life events and depression. Caspi and colleagues ${ }^{37}$ studied young adults in a large, prospective, longitudinal study and found that, among Caucasians, 1 or 2 copies of the short allele of the polymorphism reported more depressive symptoms and more frequently met criteria for major depressive disorder in relation to stressful life events from age 21 to age 26 than those who were homozygous for the long allele $(L / L)$ genotype.

Current evidence regarding the relationship between the 5-HTT gene polymorphism and diarrhea-predominant IBS, another ASD that frequently co-occurs with both fibromyalgia and major depression, is inconclusive. A few studies have reported a higher frequency of the 5HTT gene polymorphism in patients with IBS ${ }^{38,39}$ compared with healthy controls, which is consistent with evidence of altered serotonin metabolism and reuptake in these patients. ${ }^{40}$ Several studies, however, have failed to replicate these findings in patients with IBS, ${ }^{41-43}$ and 1 study found no relationship between the S/S genotype and fibromyalgia among patients without elevated levels of psychological distress. ${ }^{44}$ Nevertheless, Camilleri and colleagues ${ }^{45}$ recently reported that one or more copies of the short allele of the 5-HTT gene polymorphism were associated with increased pain sensitivity in response to rectal balloon distention. This is a very encouraging development. At present, however, there are no published studies of the relationship between the 5-HTT gene polymorphism and variations in experimental pain sensitivity. In addition, there are no studies of the relationship between the 5-HTT gene polymorphism and variations in functional activity of brain regions involved in pain processing. Nevertheless, it has been found that healthy persons with the s/s genotype, compared to those with the 1 allele, display greater activation of 2 pain processing centers in the brain (left anterior cingulate cortex and right parahippocampal gyrus) in response to colorectal balloon distention. ${ }^{46}$

Another area of investigation is the relationship between catechol-O-methyltransferase (COMT) gene variants and pain. The COMT gene encodes an enzyme that metabolizes catecholamines (ie, norepinephrine and dopamine) and thereby influences several cognitiveaffective phenotypes, including pain phenotypes. Consistent with the ASD hypothesis, COMT also has been implicated in the pathogenesis of migraine and anxiety disorders, as well as a variety of cardiovascular diseases. ${ }^{47}$ Initial studies focused on the all $^{158}$ met polymorphism, a SNP in codon 158 of the COMT gene that substitutes valine for methionine and results in reduced activity of the enzyme. Individuals who are homozygous for the met $^{158}$ allele of this polymorphism have shown diminished regional $\mu$-opioid system responses to tonic pain compared to heterozygotes; these responses have been accompanied by increased pain intensity 
ratings and more negative internal affective states. ${ }^{48}$ Opposite effects in pain and negative affect have been found in $v_{a l}{ }^{158}$ homozygotes.

Diatchenko and colleagues ${ }^{49,50}$ examined the relationship between val158met polymorphism haplotypes and the onset of TMD in healthy young women. The haplotypes were associated with low (LPS), average (APS), or high (HPS) pain sensitivity in response to thermal, ischemic, and pressure stimuli. ${ }^{49}$ Women with APS/APS or HPS/APS diplotypes were significantly more likely to develop TMD over a 3-year period than those who had at least 1 LPS haplotype.50 The predictive power of the COMT haplotypes for development of TMD was significantly enhanced when combined with high baseline levels of somatization.

No prospective studies have been conducted to date that indicate the involvement of COMT variants in the onset of fibromyalgia. However, Gürsoy and colleagues ${ }^{51}$ demonstrated that gene variants associated with relatively low or intermediate levels of COMT enzymatic activity were significantly more frequent among patients with fibromyalgia compared to healthy controls $(P<0.05)$. It was also recently reported that in Sprague-Dawley rats, enhanced mechanical and thermal pain sensitivity associated with depressed COMT activity is completely blocked by the nonselective $\beta$-adrenergic antagonist propranolol or by the combined administration of selective $\beta 2$ - and $\beta 3$-adrenergic antagonists. ${ }^{52}$

Findings from the COMT studies suggest a potential clinical role for pharmacologic agents that affect catecholaminergic activity. As reviewed by Arnold and Mease in this supplement, dopamine receptor agonists and medications that selectively inhibit the reuptake of norepinephrine have been found to be effective in treating the pain and other symptoms of fibromyalgia. Gürsoy's preclinical findings suggest the possibility of using $\beta 2$ - and $\beta 3$ adrenergic receptor blockers to treat chronic pain conditions associated with low COMT activity levels. However, the clinical relevance of these results has yet to be evaluated in patients with fibromyalgia or other chronic pain disorders.

It should be noted that, similar to the IBS literature reviewed above, there are negative as well as positive findings regarding the associations between 5-HTT and COMT polymorphisms and fibromyalgia. ${ }^{53}$ Advances in understanding the contribution of these and other gene polymorphisms to the onset of fibromyalgia and other ASDs may be facilitated by viewing these conditions as "complex genetic diseases." These disorders are influenced by multiple genes that interact with environmental risk factors (e.g., exposure to life stressors) to produce variations in symptom-related behavior (i.e., phenotypes), such as pain sensitivity and pain inhibition in response to noxious stimuli in laboratory settings. ${ }^{54}$ We encourage the development of such investigations as well as studies of the associations between gene variants and response to pharmacologic agents.

Finally, advances in fibromyalgia will be enhanced by examining candidate genes in addition to 5-HTT and COMT. For example, Buskila and colleages ${ }^{55}$ recently have begun to study relationships between the dopamine D4 receptor (DRD4) gene and fibromyalgia. These investigators demonstrated an association between fibromyalgia and the DRD4 exon III 7 repeat genotype using the same sample employed by Cohen et $\mathrm{al}^{33}$ in their study of the 5 HTT gene polymorphism. Relative to healthy controls, the frequency of the 7 repeat genotype was significantly lower in persons with fibromyalgia $(P=0.008)$. This is particularly intriguing given that women with fibromyalgia, compared to sex-matched controls, show significant reductions in presynaptic dopamine metabolism in several CNS regions where dopamine normally contributes to pain inhibition, such as the medial thalamus and the anterior cingulate cortex. ${ }^{56}$ 


\section{ENVIRONMENTAL TRIGGERS}

Environmental triggers that may be involved in the pathophysiology of fibromyalgia include mechanical/physical trauma or injury and psychosocial stressors. ${ }^{57-59}$ Commonly reported physical traumas include acute illness, physical injury, surgery, and motor vehicle accidents. Commonly reported psychosocial triggers include chronic stress, emotional trauma, and emotional, physical, or sexual abuse. ${ }^{60}$ The effects of psychosocial stressors may be especially pervasive because in addition to being associated with the onset of chronic widespread pain, they may also contribute to enhanced pain responses via involvement of the neuroendocrine system as described earlier.

\section{Physical Stressors}

In a study of 896 newly employed workers recruited from 12 diverse settings, Harkness and colleagues $^{61}$ found that physical stressors in the workplace predict the development of chronic widespread body pain. Workers who were free of pain at baseline were followed for 2 years to determine the extent to which exposure to physical and psychosocial risk factors would predict onset of widespread pain. At 12 months, the rate of new-onset widespread pain was $15 \%$, with a significant difference between women and men (19\% vs $12 \%$, respectively, $P=$ 0.012 ). At 24 months, the rate of new-onset pain was $12 \%$ with no significant gender differences. Factors associated with the occurrence of widespread pain involved manual work, such as heavy lifting, repetitive motions, or squatting for extended periods of time. The strongest predictors of new-onset widespread pain were pulling more than $56 \mathrm{~kg}$ (OR 1.8, 95\% $\mathrm{CI}=0.98-3.2)$ and squatting for more than 15 minutes (OR 2.0, 95\% CI $=1.1-3.6)$. These results are supported by findings from other studies conducted by Harkness and colleagues, $62^{-} 64$ who have reported the role of physical stressors in other pain conditions. Examples of these factors include lifting heavy weights above shoulder level (shoulder and low back pain), lifting heavy weights with 1 or both hands (shoulder and low back pain), and lifting or carrying heavy weights with 1 hand (knee pain).

\section{Psychosocial Stressors}

Harkness et al ${ }^{61}$ also investigated psychosocial stressors in the workplace and found that dissatisfaction with social support from colleagues (OR 2.2, 95\% CI $=0.8-5.8)$ and monotonous work (OR 1.9, 95\% CI $=1.1-3.2)$ were the strongest psychosocial predictors of new-onset widespread pain. Additional environmental factors, such as working in hot conditions, also tended to increase the risk of developing widespread pain, although the magnitudes of these associations were not statistically significant. As was observed with physical stressors, psychosocial stressors were found to be associated with the onset of other pain conditions. ${ }^{62-} 64$

Psychosocial stress may also affect the severity or aversiveness of pain associated with fibromyalgia, as demonstrated in a study by Davis and colleagues ${ }^{65}$ that examined the effects of mood and exposure to psychosocial stressors on reported pain. This study included women with fibromyalgia or osteoarthritis of the knee. Patients were randomly assigned to undergo a 3-minute procedure designed to induce either a negative mood (via reading sad text) or neutral mood (via relaxation). Following the mood induction procedure, subjects were asked to discuss for 30 minutes a stressful event that had occurred in their lives. It was found that prolonged discussion of stressful events did not alter the clinical pain ratings among women who had first undergone neutral mood induction, regardless of whether they had fibromyalgia or osteoarthritis of the knee. However, women with fibromyalgia who underwent negative mood induction prior to discussing stressful events reported significantly greater increases in their clinical pain compared to their counterparts with osteoarthritis of the knee. Moreover, women with fibromyalgia who underwent neutral mood induction, compared to those who underwent 
negative mood induction, reported greater decreases in pain intensity ratings during recovery from stressor exposure.

The observations of Davis and colleagues raise an important question. Do patients' reports of stressor-evoked increases in clinical pain ratings reflect alterations in their sensory perceptions of pain intensity, pain aversiveness, or both? Independent studies of patients with fibromyalgia and healthy persons have indicated that negative mood induction and exposure to stressors prior to or during exposure to noxious tonic stimuli produce significant increases in ratings of pain aversiveness but do not alter ratings of the sensory intensity of pain.66,67 These finding suggest that negative mood states and exposure to psychosocial stressors enhance the affective components of pain responses (i.e., aversiveness, unpleasantness) among women with fibromyalgia.

\section{CONCLUSION}

Factors contributing to the pathophysiology of fibromyalgia include abnormal function of the autonomic and neuroendocrine systems, genetic influences, and environmental triggers such as exposure to stressors. These factors are also usually associated with disorders that co-occur or overlap with fibromyalgia, such as MDD, IBS, and TMD. Alterations in central processing of sensory input and deficits in endogenous pain inhibition may also contribute to the enhanced pain sensitivity and persistence of widespread pain in persons with fibromyalgia. It is expected that advances in understanding the pathophysiology of fibromyalgia and other forms of ASD will contribute to the development and validation of efficacious pharmacologic and behavioral treatments for these disorders. These advances also will help physicians and allied health professionals provide their patients with clear expectations regarding treatment and outcomes.

\section{References}

1. Hudson JI, Mangweth B, Pope HG Jr, et al. Family study of affective spectrum disorder. Arch Gen Psychiatry 2003;60:170-177. [PubMed: 12578434]

2. Hudson JI, Arnold LM, Keck PE Jr, et al. Family study of fibromyalgia and affective spectrum disorder. Biol Psychiatry 2004;56:884-891. [PubMed: 15576066]

3. Arnold LM, Hudson JI, Hess EV, et al. Family study of fibromyalgia. Arthritis Rheum 2004;50:944952. [PubMed: 15022338]

4. Aaron LA, Buchwald D. Chronic diffuse musculoskeletal pain, fibromyalgia and co-morbid unexplained clinical conditions. Best Pract Res Clin Rheumatol 2003;17:563-574. [PubMed: 12849712]

5. Arnold LM, Hudson JI, Keck PE, et al. Comorbidity of fibromyalgia and psychiatric disorders. J Clin Psychiatry 2006;67:1219-1225. [PubMed: 16965199]

6. Weir PT, Harlan GA, Nkoy FL, et al. The incidence of fibromyalgia and its associated comorbidities: a population-based retrospective cohort study based on International Classification of Diseases, 9th Revision codes. J Clin Rheumatol 2006;12:124-128. [PubMed: 16755239]

7. Carli G, Suman AL, Biasi G, Marcolongo R. Reactivity to superficial and deep stimuli in patients with chronic musculoskeletal pain. Pain 2002;100:259-269. [PubMed: 12467997]

8. Nielsen LA, Henriksson KG. Pathophysiological mechanisms in chronic musculoskeletal pain (fibromyalgia): the role of central and peripheral sensitization and pain disinhibition. Best Pract Res Clin Rheumatol 2007;21:465-480. [PubMed: 17602994]

9. Watkins LR, Milligan ED, Maier SF. Glial activation: a driving force for pathological pain. Trends Neurosci 2001;24:450-455. [PubMed: 11476884]

10. Kelly DJ, Ahmad M, Brull SJ. Preemptive analgesia I: physiological pathways and pharmacological modalities. Can J Anaesth 2001;48:1000-1010. [PubMed: 11698320]

11. Ledeboer A, Liu T, Shumilla JA, et al. The glial modulatory drug AV411 attenuates mechanical allodynia in rat models of neuropathic pain. Neuron Glia Biol 2006;2:279-291. [PubMed: 18176632] 
12. Watkins LR, Milligan ED, Maier SF. Glial proinflammatory cytokines mediate exaggerated pain states: implications for clinical pain. Adv Exp Med Biol 2003;521:1-21. [PubMed: 12617561]

13. Gracely RH, Petzke F, Wolf JM, Clauw DJ. Functional magnetic resonance imaging evidence of augmented pain processing in fibromyalgia. Arthritis Rheum 2002;46:1333-1343. [PubMed: 12115241]

14. Russell IJ, Michalek JE, Vipraio GA, et al. Platelet 3H-imipramine uptake receptor density and serum serotonin levels in patients with fibromyalgia/fibrositis syndrome. J Rheumatol 1992;19:104-109. [PubMed: 1313504]

15. Russell IJ, Vaeroy H, Javors M, Nyberg F. Cerebrospinal fluid biogenic amine metabolites in fibromyalgia/fibrositis syndrome and rheumatoid arthritis. Arthritis Rheum 1992;35:550-556. [PubMed: 1374252]

16. McCain GA, Tilbe KS. Diurnal hormone variation in fibromyalgia syndrome: a comparison with rheumatoid arthritis. J Rheumatol Suppl 1989;19:154-157. [PubMed: 2607509]

17. Crofford LJ, Pillemer SR, Kalogeras KT, et al. Hypothalamic-pituitary-adrenal axis perturbations in patients with fibromyalgia. Arthritis Rheum 1994;37:1583-1592. [PubMed: 7980669]

18. Harris RE, Williams DA, McLean SA, et al. Characterization and consequences of pain variability in individuals with fibromyalgia. Arthritis Rheum 2005;52:3670-3674. [PubMed: 16258905]

19. Vaeroy H, Qiao ZG, Morkrid L, Forre O. Altered sympathetic nervous system response in patients with fibromyalgia (fibrositis syndrome). J Rheumatol 1989;16:1460-1465. [PubMed: 2689647]

20. Bou-Holaigah I, Calkins H, Flynn JA, et al. Provocation of hypotension and pain during upright tilt table testing in adults with fibromyalgia. Clin Exp Rheumatol 1997;15:239-246. [PubMed: 9177917]

21. Martinez-Lavin M, Hermosillo AG, Rosas M, Soto ME. Circadian studies of autonomic nervous balance in patients with fibromyalgia: a heart rate variability analysis. Arthritis Rheum 1998;41:1966-1971. [PubMed: 9811051]

22. Stein PK, Domitrovich PP, Ambrose K, et al. Sex effects on heart rate variability in fibromyalgia and Gulf War illness. Arthritis Rheum 2004;51:700-708. [PubMed: 15478168]

23. Roizenblatt S, Moldofsky H, Benedito-Silva AA, Tufik S. Alpha sleep characteristics in fibromyalgia. Arthritis Rheum 2001;44:222-230. [PubMed: 11212164]

24. Harding SM. Sleep in fibromyalgia patients: subjective and objective findings. Am J Med Sci 1998;315:367-376. [PubMed: 9638893]

25. Van Cauter E, Plat L, Copinschi G. Interrelations between sleep and the somatotropic axis. Sleep 1998;21:553-566. [PubMed: 9779515]

26. Prinz PN, Moe KE, Dulberg EM, et al. Higher plasma IGF-1 levels are associated with increased delta sleep in healthy older men. J Gerontol A Biol Sci Med Sci 1995;50:M222-226. [PubMed: 7614245]

27. Bennett RM, Clark SR, Campbell SM, Burckhardt CS. Low levels of somatomedin C in patients with the fibromyalgia syndrome. A possible link between sleep and muscle pain. Arthritis Rheum 1992;35:1113-1116. [PubMed: 1418002]

28. Davies KA, Macfarlane GJ, Nicholl BI, et al. Restorative sleep predicts the resolution of chronic widespread pain: results from the EPIFUND study. Rheumatology (Oxford) 2008;47:1809-1813. [PubMed: 18842606]

29. Raphael KG, Janal MN, Nayak S, et al. Familial aggregation of depression in fibromyalgia: a community-based test of alternate hypotheses. Pain 2004;110:449-460. [PubMed: 15275798]

30. Wolfe F, Smythe HA, Yunus MB, et al. The American College of Rheumatology 1990 Criteria for the Classification of Fibromyalgia. Report of the Multicenter Criteria Committee. Arthritis Rheum 1990;33:160-172. [PubMed: 2306288]

31. Kato K, Sullivan PF, Evengard B, Pedersen NL. Importance of genetic influences on chronic widespread pain. Arthritis Rheum 2006;54:1682-1686. [PubMed: 16646040]

32. Offenbaecher M, Bondy B, de Jonge S, et al. Possible association of fibromyalgia with a polymorphism in the serotonin transporter gene regulatory region. Arthritis Rheum 1999;42:24822488. [PubMed: 10555044]

33. Cohen H, Buskila D, Neumann L, Ebstein RP. Confirmation of an association between fibromyalgia and serotonin transporter promoter region (5-HTTLPR) polymorphism, and relationship to anxietyrelated personality traits. Arthritis Rheum 2002;46:845-847. [PubMed: 11920428] 
34. Bradley L, Fillingim R, Sotolongo A, et al. Family aggregation of pain sensitivity in fibromyalgia [abstract]. J Pain 2006;7(suppl 1):S1.

35. Hoefgen B, Schulze TG, Ohlraun S, et al. The power of sample size and homogenous sampling: association between the 5-HTTLPR serotonin transporter polymorphism and major depressive disorder. Biol Psychiatry 2005;57:247-251. [PubMed: 15691525]

36. Eaton WW, Shao H, Nestadt G, et al. Population-based study of first onset and chronicity in major depressive disorder. Arch Gen Psychiatry 2008;65:513-520. [PubMed: 18458203]

37. Caspi A, Sugden K, Moffitt TE, et al. Influence of life stress on depression: moderation by a polymorphism in the 5-HTT gene. Science 2003;301:386-389. [PubMed: 12869766]

38. Yeo A, Boyd P, Lumsden S, et al. Association between a functional polymorphism in the serotonin transporter gene and diarrhoea predominant irritable bowel syndrome in women. Gut 2004;53:14521458. [PubMed: 15361494]

39. Park JM, Choi MG, Park JA, et al. Serotonin transporter gene polymorphism and irritable bowel syndrome. Neurogastroenterol Motil 2006;18:995-1000. [PubMed: 17040410]

40. Atkinson W, Lockhart S, Whorwell PJ, et al. Altered 5-hydroxytryptamine signaling in patients with constipation- and diarrhea-predominant irritable bowel syndrome. Gastroenterology 2006;130:3443. [PubMed: 16401466]

41. Camilleri M. Is there a SERT-ain association with IBS? Gut 2004;53:1396-1399. [PubMed: 15361483]

42. Colucci R, Blandizzi C, Bellini M, et al. The genetics of the serotonin transporter and irritable bowel syndrome. Trends Mol Med 2008;14:295-304. [PubMed: 18550438]

43. Van Kerkhoven LA, Laheij RJ, Jansen JB. Meta-analysis: a functional polymorphism in the gene encoding for activity of the serotonin transporter protein is not associated with the irritable bowel syndrome. Aliment Pharmacol Ther 2007;26:979-986. [PubMed: 17877505]

44. Gursoy S. Absence of association of the serotonin transporter gene polymorphism with the mentally healthy subset of fibromyalgia patients. Clin Rheumatol 2002;21:194-197. [PubMed: 12111622]

45. Camilleri M, Busciglio I, Carlson P, et al. Candidate genes and sensory functions in health and irritable bowel syndrome. Am J Physiol Gastrointest Liver Physiol 2008;295:G219-225. [PubMed: 18511740]

46. Fukudo S, Kanazawa M, Mizuno T, et al. Impact of serotonin transporter gene polymorphism on brain activation by colorectal distention. Neuroimage 2009;47:946-951. [PubMed: 19426812]

47. Diatchenko L, Nackley AG, Tchivileva IE, et al. Genetic architecture of human pain perception. Trends Genet 2007;23:605-613. [PubMed: 18023497]

48. Zubieta JK, Heitzeg MM, Smith YR, et al. COMT val ${ }^{158}$ met genotype affects mu-opioid neurotransmitter responses to a pain stressor. Science 2003;299:1240-1243. [PubMed: 12595695]

49. Diatchenko L, Nackley AG, Slade GD, et al. Catechol-O-methyltransferase gene polymorphisms are associated with multiple pain-evoking stimuli. Pain 2006;125:216-224. [PubMed: 16837133]

50. Diatchenko L, Slade GD, Nackley AG, et al. Genetic basis for individual variations in pain perception and the development of a chronic pain condition. Hum Mol Genet 2005;14:135-143. [PubMed: 15537663]

51. Gursoy S, Erdal E, Herken H, et al. Significance of catechol-O-methyltransferase gene polymorphism in fibromyalgia syndrome. Rheumatol Int 2003;23:104-107. [PubMed: 12739038]

52. Nackley AG, Tan KS, Fecho K, et al. Catechol-O-methyltransferase inhibition increases pain sensitivity through activation of both beta2- and beta3-adrenergic receptors. Pain 2007;128:199-208. [PubMed: 17084978]

53. Tander B, Gunes S, Boke O, et al. Polymorphisms of the serotonin-2A receptor and catechol-Omethyltransferase genes: a study on fibromyalgia susceptibility. Rheumatol Int 2008;28:685-691. [PubMed: 18196244]

54. Saito YA, Talley NJ. Genetics of irritable bowel syndrome. Am J Gastroenterol 2008;103:2100-2104. quiz 2105. [PubMed: 18684190]

55. Buskila D, Cohen H, Neumann L, Ebstein RP. An association between fibromyalgia and the dopamine D4 receptor exon III repeat polymorphism and relationship to novelty seeking personality traits. Mol Psychiatry 2004;9:730-731. [PubMed: 15052273] 
56. Wood PB, Patterson JC 2nd, Sunderland JJ, et al. Reduced presynaptic dopamine activity in fibromyalgia syndrome demonstrated with positron emission tomography: a pilot study. J Pain 2007;8:51-58. [PubMed: 17023218]

57. Al-Allaf AW, Dunbar KL, Hallum NS, et al. A case-control study examining the role of physical trauma in the onset of fibromyalgia syndrome. Rheumatology (Oxford) 2002;41:450-453. [PubMed: 11961177]

58. Cruz BA, Catalan-Soares B, Proietti F. Higher prevalence of fibromyalgia in patients infected with human T cell lymphotropic virus type I. J Rheumatol 2006;33:2300-2303. [PubMed: 17086610]

59. Demitrack MA, Crofford LJ. Evidence for and pathophysiologic implications of hypothalamicpituitary-adrenal axis dysregulation in fibromyalgia and chronic fatigue syndrome. Ann N Y Acad Sci 1998;840:684-697. [PubMed: 9629295]

60. Bennett RM, Jones J, Turk DC, et al. An internet survey of 2,596 people with fibromyalgia. BMC Musculoskelet Disord 2007;8:27. [PubMed: 17349056]

61. Harkness EF, Macfarlane GJ, Nahit E, et al. Mechanical injury and psychosocial factors in the work place predict the onset of widespread body pain: a two-year prospective study among cohorts of newly employed workers. Arthritis Rheum 2004;50:1655-1664. [PubMed: 15146437]

62. Harkness EF, Macfarlane GJ, Nahit ES, et al. Risk factors for new-onset low back pain amongst cohorts of newly employed workers. Rheumatology (Oxford) 2003;42:959-968. [PubMed: 12730508]

63. Harkness EF, Macfarlane GJ, Nahit ES, et al. Mechanical and psychosocial factors predict new onset shoulder pain: a prospective cohort study of newly employed workers. Occup Environ Med 2003;60:850-857. [PubMed: 14573715]

64. Jones GT, Harkness EF, Nahit ES, et al. Predicting the onset of knee pain: results from a 2-year prospective study of new workers. Ann Rheum Dis 2007;66:400-406. [PubMed: 16935910]

65. Davis MC, Zautra AJ, Reich JW. Vulnerability to stress among women in chronic pain from fibromyalgia and osteoarthritis. Ann Behav Med 2001;23:215-226. [PubMed: 11495222]

66. Loggia ML, Mogil JS, Bushnell MC. Experimentally induced mood changes preferentially affect pain unpleasantness. J Pain 2008;9:784-791. [PubMed: 18538637]

67. Okonkwo R, Bradley L, Sotolongo A, et al. Effect of stressful imagery on thermal pain ratings of patients with fibromyalgia: what mediates this relationship? J Pain 2007:8. 


\section{A. Pain Pathways}

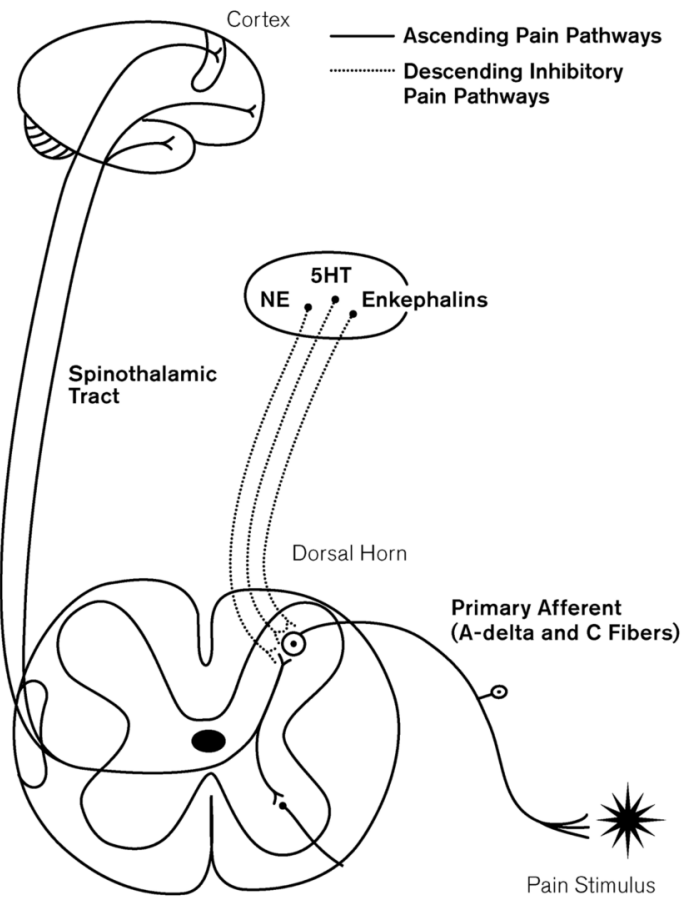

\section{B. Normal Pain Processing}

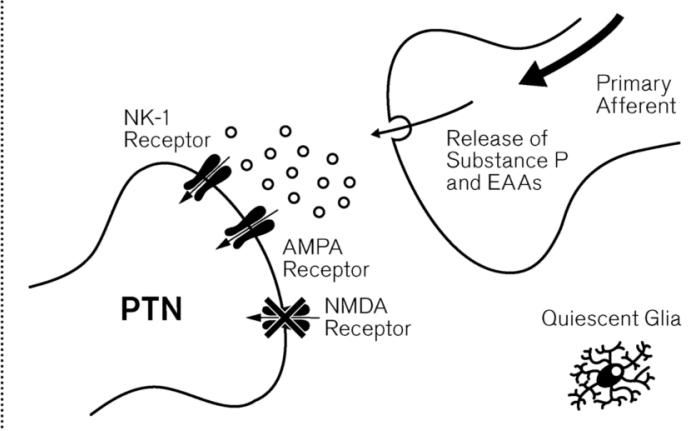

\section{Abnormal Pain Processing}

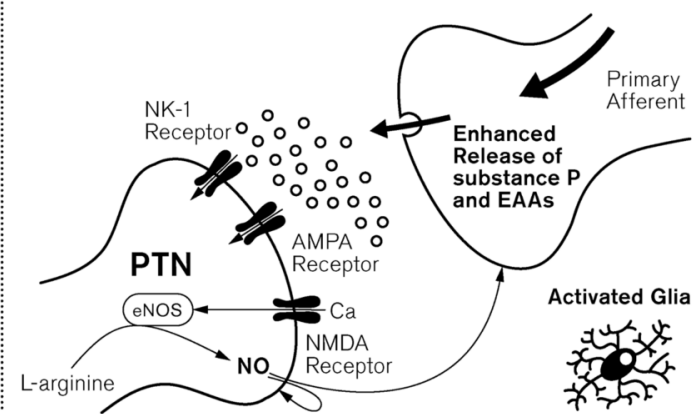

Figure 1.

(A) In the classical model of acute pain, painful stimuli are transmitted from the periphery to the dorsal horn via primary afferent fibers ( $\alpha-\delta$ and $C$ nerve fibers) and from the dorsal horn to the brain via the spinothalamic tract. Pain perception is modulated through the activation of descending inhibitory pathways and the release of neurotransmitters such as norepinephrine, serotonin, and opiate-like substances (endorphins). (B) In the dorsal horn, incoming afferent pain signals cause the release of substance $\mathrm{P}$ and excitatory amino acids (EAAs), which bind to activate postsynaptic receptors on the pain transmission neurons (PTNs). Glia are present but quiescent. (C) With intense or prolonged exposure to painful stimuli, incoming afferent signals are increased, and presynaptic release of substance $\mathrm{P}$ and EAAs is enhanced. An influx of $\mathrm{Ca}^{2+}$ increases the production of nitric oxide, which diffuses out of the PTN and causes the PTN to become hyperexcitable and further enhances the presynaptic release of EAAs and substance P. Glia cells become activated and release substances (e.g., nitric oxide, reactive oxygen species, prostaglandins, proinflammatory cytokines, nerve growth factor) that further increase presynaptic release and postsynaptic hyperexcitability. PTN = pain transmission neuron; EAA = excitatory amino acid; 5-HT = serotonin; $\mathrm{NE}=$ norepinephrine; $\mathrm{NMDA}=N$ methyl-D-aspartic acid; AMPA = alpha-amino-3-hydroxy-5-methyl-4-isoxazolepropionic acid; NK-1 = neurokinin; $\mathrm{cNOS}=$ constitutive nitric oxide synthase; $\mathrm{NO}=$ nitric oxide. (Adapted with permission from Trends Neurosci ${ }^{9}$ and from Can J Anaesth ${ }^{10}$ with kind permission from Springer Science and Business Media.) 